\title{
1 \\ HACER DECIR AL TEXTO BÍBLICO. TRANSPARENCIA Y OPACIDAD EN LA DISPUTA POR LA ADMINISTRACIÓN DE LA PALABRA SAGRADA
}

Martín Miguel Acebal

martinacebal@gmail.com / Profesor y licenciado en Letras por la Universidad Nacional del Litoral y doctor en Lingüística por la Universidad de Buenos Aires. Es docente investigador en la Universidad Nacional del Litoral y en la Universidad de Flores. 


\section{RESUMEN}

El artículo analiza un grupo de estrategias discursivas identificadas en homilías católicas pronunciadas en la iglesia Nuestra Señora Del Carmen de la ciudad de Santa Fe (Argentina). El trabajo busca mostrar el modo en que las homilías despliegan diferentes recursos para la incorporación de la paráfrasis del texto bíblico. Con este objetivo, el análisis parte de una serie de cláusulas con procesos verbales, en las cuales el texto bíblico ocupa el rol de agente. Uno de los objetivos del artículo es demostrar que esta agentivación se inscribe en un campo de fuerzas propio del discurso religioso católico, en el cual las estrategias se encuentran tensionadas por la construcción de efectos de transparencia y de opacidad sobre el propio texto bíblico. En una segunda instancia, el texto presenta una tabla que compara los resultados de las homilías de la iglesia Nuestra Señora Del Carmen con los obtenidos en análisis semejantes sobre otras iglesias de la ciudad. Lo que la tabla muestra es una gradual complejización y opacidad del texto bíblico a medida que la producción de las homilías se desplaza de los sectores céntricos a los periféricos. Finalmente, el artículo propone una hipótesis contextual destinada a explicar este fenómeno relevado.

\section{PALABRAS CLAVE}

$>$ discurso religioso

$>$ homilía

$>$ texto bíblico

$>$ estrategia discursiva

$>$ transparencia / opacidad 
ABSTRACT

The article analyzes a group of discursive strategies identified in Catholic homilies in the church Nuestra Señora Del Carmen, located in Santa Fe city (Argentina). The work aims to show how homilies deploy different resources to incorporate biblical text paraphrase. To this end, the analysis parts from a series of clauses with verbal processes, in which the biblical text takes up the role of agent. One of the objetives of the article is to show that this agentivación joins a field of own forces of Catholic religious discourse, in which strategies are tensioned by building effects of transparency and opacity on the biblical text itself. In a second instance, the text presents a table comparing the results of the homilies in the church Nuestra Señora Del Carmen with those obtained in other churches in the city. The table shows a gradual complexity and opacity of the biblical text as homilies production shifts from central to peripheral areas. Finally, the article proposes a contextual hypotheses designed to explain this phenomenon.

\section{KEY WORDS}

$>$ religious discourse

$>$ homily

$>$ Biblical text

$>$ discursive strategy

$>$ transparency / opacity 


\section{INTRODUCCIÓN}

El presente artículo propone una herramienta metodológica para el análisis de algunos de los vínculos que mantiene la homilía católica con sus condiciones de producción institucionales, genéricas y situacionales, y en especial con aquellas relativas a la dialéctica que se establece entre la autorización y la adecuación en el discurso sacerdotal.

La caracterización de la homilía como práctica discursiva demanda un ejercicio de extrañamiento, de distanciamiento de una actividad religiosa y de una institución que se ha construido discursivamente como hegemónica en la sociedad argentina (Frigerio, 2007). En este sentido, la definición de la homilía no es tampoco una actividad libre de sobreentendidos e invisibilizaciones. Al formar parte de la misa católica, la homilía tiende a adquirir las cualidades de esta práctica litúrgica altamente ritualizada. Esto le permite al analista recuperar las codificaciones realizadas por la misma Iglesia Católica en la Instrucción General del Misal Romano. En este marco, el discurso homilético es parte de la "Liturgia de la Palabra", que junto con la "Liturgia Eucarística" conforma las dos partes constitutivas de la misa católica. La Liturgia de la Palabra se ordena, a su vez, en: las lecturas bíblicas; los cantos interleccionales; la homilía; la profesión de fe; y la oración de los fieles.

Estas normativas ofrecen una regularidad operativa para el registro de los discursos: permiten reconocer con facilidad su comienzo y su finalización, a la vez que los constituyen en entidades ordenadas, unificadas y delimitadas. Son estos parámetros los que hemos seguido, como veremos, para la conformación de nuestro corpus, y también son estas primeras coordenadas las que nos permiten identificar una esfera del uso de la lengua capaz de producir tipos relativamente estables de enunciados, es decir, las que nos permiten hablar de la homilía católica como un género discursivo (Bajtin, 2008 [1979]).

En esta perspectiva, la homilía ha sido caracterizada como una actividad de reformulación y actualización del texto bíblico (Arnoux, 2003; Arnoux y Blanco, 2002, 2004), en especial de aquellos pasajes que forman parte del rito de la misa y que constituyen las "lecturas bíblicas" dentro de la Liturgia de la Palabra. Lo que la homilía hace, en suma, es volver a decir el texto sagrado y aproximarlo a los fieles y a sus circunstancias. 
Sin embargo, este tipo de abordaje de los géneros, que refuerza su carácter institucional y codificado, tiende a pasar por alto, como señalan Briggs y Bauman (1996), que "el ajuste entre un texto particular y su modelo genérico, y aun con otros textos del mismo género, nunca es perfecto, sino que presenta siempre algunas grietas", y que "los moldes genéricos (...) nunca proveen medios suficientes de producción y recepción del discurso" (1996:91). En este sentido, aunque hemos atendido a los parámetros institucionales para la conformación de nuestro corpus, el análisis discursivo de carácter estratégico (Menéndez, 2004, 2006) que presentaremos en esta tesis necesitará prestar una especial atención a esas brechas que se abren entre el modelo o el esquema genérico y la homilía particular.

\section{ACERCA DEL CORPUS}

Cuando afirmamos el carácter insuficiente de los parámetros genéricos para una total producción y recepción del discurso, también estamos sugiriendo que el análisis discursivo requiere no sólo de la atención a los rasgos específicos y al espacio de tensiones que despliega la homilía, sino también a elementos contextuales que vienen a complementar el abordaje genérico. En este artículo en particular consideraremos el rol que tiene la heterogeneidad de los destinatarios en la explicación de las estrategias discursivas. Con este fin, nuestro corpus está conformado por la desgrabación de 20 homilías registradas en cuatro iglesias católicas diferentes de la ciudad de Santa Fe, a razón de cinco homilías por iglesia, durante los años 2004 y 2005. ${ }^{1}$ Dado que el objetivo es trabajar las estrategias de adecuación a esos diferentes contextos, la decisión fue realizar un recorrido gradual que va de una iglesia netamente céntrica iglesia Nuestra Señora del Carmen-, con una concurrencia mayoritariamente de personas pertenecientes a sectores sociales de la clase alta o media alta; una menos céntrica - Sagrado Corazón de Jesús—, con concurrencia de clase media; una barrial —Nuestra Señora de La Merced-, con concurrencia de

\footnotetext{
${ }^{1}$ Ver "Referencias del corpus", al final del artículo.
} 
clase media baja; y una más periférica, con concurrencia de sectores sociales populares - Nuestra Señora de Lourdes-. El número de homilías registradas en cada iglesia se debe a que el mismo se considera un volumen lo suficientemente representativo (Hunston, 2002) de las estrategias implementadas en cada una de las iglesias. Otro de los objetivos del número de registros fue poder establecer regularidades que trascendieran los rasgos estilísticos del sacerdote particular. De este modo, en casi todas las parroquias seleccionadas fue posible registrar más de un sacerdote a cargo del oficio religioso. Este aspecto nos permite atribuir parte de estas regularidades al lugar de producción institucional, antes que a las características particulares del hablante.

Las homilías registradas fueron pronunciadas en los oficios correspondientes a los días sábados o domingos, durante los cuales el rito de la misa se realiza de un modo regular. Los registros fueron realizados expresamente para esta investigación. La observación es significativa porque permite establecer una relación directa entre la situación de producción del discurso y su registro, algo que suele perderse luego de los procesos de normalización que se realizan en la publicación de esta clase de discursos.

\section{HIPÓTESIS}

El objetivo de nuestra investigación consistió en la demostración de dos hipótesis complementarias:

$>$ Que toda estrategia discursiva puede ser (teóricamente) y debe ser (metodológicamente) puesta en relación con un determinado conflicto que el analista le atribuye al sujeto discursivo en la búsqueda de un propósito comunicativo. La identificación de lo que llamaremos la conflictividad estratégica constituye, así, el rasgo clave en la explicación de la elección de los recursos involucrados en una estrategia discursiva.

$>$ Que gran parte de las estrategias discursivas identificables en las homilías católicas estudiadas pueden explicarse por la tensión — conflictividad estratégica- que se establece entre el polo de la autorización y el de la adecuación en 
el discurso del sacerdote. Mientras el primero tiende hacia un distanciamiento entre el sujeto discursivo y sus destinatarios, el segundo orienta hacia la aproximación de los participantes.

Parte de la organización de este artículo toma la forma de esta doble orientación perseguida por sus hipótesis: por una parte, la caracterización de una concepción particular de estrategia discursiva; por otra, la especificación de las condiciones conflictivas en que se desarrollan las homilías del corpus y el análisis de algunas de las estrategias donde se reconoce esta conflictividad. En este último punto, presentaremos el análisis de un conjunto de estrategias discursivas que hemos relevado en nuestros corpus y que consideramos adecuadas para la actividad de puesta a prueba y mostración de nuestras hipótesis. Por razones de espacio sólo presentaremos el análisis de las estrategias en sólo uno de los grupos de homilías, el correspondiente a la iglesia Nuestra Señora del Carmen. No obstante, sí incluiremos una contrastación de las regularidades de los cuatro grupos entre sí, lo que nos permitirá identificar un fenómeno de complejización, enriquecimiento y desigual distribución de los recursos estratégicos. Llegados a este punto propondremos una posible explicación de estas diferencias a partir de la consideración de las particularidades de los destinatarios de cada grupo de homilías, así como de sus relaciones con el campo religioso y las diferentes formas de religiosidad.

\section{ACERCA DEL CONCEPTO DE ESTRATEGIA}

Una estrategia discursiva puede ser entendida, en una primera instancia, como una acción discursiva singular y contingente, constituida por la particular selección de determinados elementos lingüístico-discursivos. Esta acción se explica como el producto de una percepción y evaluación de la situación como "horizonte de posibilidad" para la realización de un propósito y para los propios medios que constituyen la estrategia. Parte de esta percepción consiste en la identificación de un componente conflictivo, lo que le otorga a la estrategia un carácter de equilibro precario y una permanente tensión. La percepción de 
la plausibilidad del propósito como de los medios que articula la estrategia dependen una habilidad preconsciente que podemos asociar con el habitus bourdiano (Bourdieu, 1980, 1985, 1987).

De esta manera, la estrategia se completa con una concepción de sujeto dotado de una disposición a actuar configurada por el mismo ámbito o campo en el que se realiza la acción. Todo esto vuelve a la estrategia discursiva una acción doblemente contingente: por una parte porque la percepción y su relación con una disposición permiten que pueda ser de otra manera; por otra, porque la permanente amenaza de la conflictividad hace que los medios puedan volverse inadecuados, inestables e irreductibles una organización cerrada, acabada y, como veremos, coherente.

\section{LA ESTRATEGIA DISCURSIVA COMO COORDINACIÓN DE RECURSOS GRAMÁTICO-DISCURSIVOS}

Una estrategia discursiva es también el resultado de efectivas elecciones de los medios adecuados para alcanzar un determinado fin y salvar - como hemos anticipado e intentaremos demostrar aquí- una conflictividad percibida. Para clarificar este punto, nos valdremos de los desarrollos de Salvio Martín Menéndez (1997, 1998, 2000, 2002, 2004, 2005) sobre el concepto de "estrategia discursiva", quien la entiende como coordinación de recursos lingüístico-discursivos.

Menéndez considera que el análisis del lenguaje supone dos perspectivas diferentes pero complementarias: una es la gramatical; la otra, la estratégica. ${ }^{2}$ Dice este autor: "Ambas se presuponen y condicionan mutuamente. No hay gramática sin estrategias discursivas. Tampoco las estrategias pueden conformarse sin los recursos que la gramática provee" (2004). Esta primera observación permite tomar partido dentro de una discusión que se ha desarrollado en el ámbito del Análisis del Discurso acerca de la exigencia o no de una clase particular de

\footnotetext{
2 En textos posteriores (Menéndez, 2005) incorporará una tercera, la crítico-interpretativa, dentro de la cual se enmarcarían los trabajos del denominado Análisis Crítico del Discurso (Fairclough, 1998 [1989], 1992; Wodak y Meyer, 2003 [2001]).
} 
gramática en esta disciplina. Para Menéndez el análisis del discurso o, más precisamente, el análisis estratégico del discurso, debe valerse, necesariamente, de una gramática que comparta el interés epistemológico del Análisis del Discurso por la "opcionalidad", en tanto muestra del carácter inherentemente variable del lenguaje y su inscripción socio-cognitiva (Menéndez, 2005). Desde este punto de vista, considera adecuada la elección de una gramática sistémico-funcional (Halliday, 1994 [1985]; Halliday y Mathiessen, 2004) como complemento de la perspectiva estratégica en el análisis del lenguaje, y hace propias las palabras de Halliday cuando señalaba: "A discourse analysis that is not based on grammar is not an analysis at all, but simply a running commentary of text" (Halliday, 1985: XVl; citado por Menéndez [2006:22]).

La complementariedad entre el abordaje gramatical y el estratégico no le impide a este autor reconocer, al menos a los fines analíticos, la posibilidad de una distinción entre ambos. Dicha distinción se establece principalmente por medio de la identificación de la unidad de análisis. Así, el abordaje gramatical tiene por objeto (al menos en el marco del Análisis del Discurso) al texto, en tanto particular realización de las opciones disponibles en la gramática de una lengua. El abordaje estratégico o estratégico-pragmático tiene por objeto al discurso, el cual es entendido como un texto más un sujeto discursivo (Menéndez, 1997:524). Dice este autor, "un discurso es un proceso en el que un hablante se constituye en sujeto discursivo al producir un texto" (1998: 139). En esta perspectiva, las opciones efectivamente realizadas en el texto devienen en recursos estratégicos del discurso.

\section{ESTRATEGIAS Y RECURSOS}

En el marco de la construcción de su noción de estrategia discursiva, la inclusión del sujeto que realiza Menéndez le permite la incorporación de un cúmulo de recursos (Menéndez, 1998:140) que trascienden a los estrictamente gramaticales (en el sentido de que "no están inscriptos de manera directa en la gramática" [Menéndez, 2004]), y con esto la perspectiva pragmática en el análisis discursivo (Verschueren, 1999). 
Para este autor la atención a los recursos involucrados permite salvar las limitaciones que tiene la definición de las estrategias de Brown y Levinson, quienes las entienden como medios que permiten realizar fines comunicativos (1989 [1978]:58), pero no precisan, como dice Menéndez (2000:926), a qué "medios" se refieren estos autores. Para resolver esta limitación, decide proponer cuáles son los recursos que permiten realizar estratégicamente un fin comunicativo. Dichos recursos son agrupables, como anticipamos, en dos clases, según su grado de inscripción en la gramática de una lengua, lo que propone considerar: a) los recursos gramaticales; b) los pragmático-discursivos. Los primeros, dice Menéndez, "son opciones obligatorias que el hablante/escritor debe llevar a cabo para producir el texto y, en consecuencia, el discurso" (Menéndez, 2004). Los segundos surgen de la inclusión del sujeto, lo que permite incorporar otra clase de recursos, cuya relación con la gramática no es tan directa ni necesaria como en la primera clase (supuestos, fuerza ilocucionaria, inferencia, figura tonal, etcétera).

Con esto, es posible transformar el concepto de estrategia en una herramienta metodológica que permita ir más allá de la identificación de un fin discursivo, para poder dar cuenta de cuáles son los medios de los que se vale concretamente el sujeto discursivo para su realización estratégica.

\section{LA ESTRATEGIA COMO RECONSTRUCCIÓN DEL ANALISTA}

En el marco de los comentarios y desarrollos que acabamos de referir, Menéndez plantea la noción de "estrategia discursiva" de la siguiente manera:

una estrategia discursiva es una reconstrucción analítica de un plan de acción que el hablante/escritor en tanto sujeto discursivo pone en funcionamiento cuando combina un conjunto de recursos gramaticales y discursivos para obtener una finalidad interaccional. (2004:45)

Como vemos, en su formulación más acabada, la definición de estrategia discursiva reúne los componentes en los que nos detuvimos previamente: los recursos gramaticales y discursivos (combinados) y el mismo sujeto discursivo. 
Pero, a la vez, incorpora algunos elementos más: la asociación entre estrategia y plan y, en segundo término, la idea de que la estrategia es una reconstrucción que realiza el analista. Así, debemos decir que, desde nuestro punto de vista, la idea de entender a la estrategia como un plan de acción necesariamente conformado por más de un recurso es una forma de anticipar en el mismo concepto no tanto el lugar del sujeto discursivo, sino el de analista. El analista es aquel que puede intervenir sobre la continuidad del discurso para identificar de qué modo partes que se presentan dispersas y parecen inconexas pueden reunirse bajo un mismo hilo conductor, leerse como partes de un "plan". El analista es el único capaz de, como decía Bourdieu, "sincronizar" el discurso, esto es, disponer en un mismo tiempo y, si se quiere, en un mismo espacio, las diferentes elecciones de recursos realizadas a lo largo del discurso.

Lo anterior no pretende más que señalar algo, por lo demás, ya reconocido en el ámbito del Análisis del Discurso: que la mirada del analista no es homologable con la del participante. Lo que sí nos interesa observar es que esta diferencia no debería hacer incurrir a los análisis estratégicos en las mismas exigencias de coherencia y orden lógico de los análisis más "codificadores" del lenguaje. Sobre esto señala Bourdieu:

Es necesario reconocer a la práctica una lógica que no es la de la lógica, para evitar pedirle más lógica de la que puede dar y condenarse así bien a extraerle incoherencias, bien a imponerle una coherencia forzada. (Bourdieu, 1991 [1980]:145-146)

De este modo, el carácter reconstruido de la estrategia discursiva no abandona la pretensión de devolverle a la práctica su propia lógica, forjada sobre urgencias y tensiones que las sincronizaciones pueden tender a obturar. En suma, las reconstrucciones estratégicas deben ser permeables, como intentaremos demostrar aquí, a las conflictividades que enfrenta el sujeto discursivo y al modo en que las mismas explican las elecciones, en algunos casos de un modo más efectivo que lo que lo hace su reducción a una finalidad interaccional. De ahí nuestro interés por atribuir a la conflictividad el carácter de componente inherente a la noción de estrategia discursiva y aspecto insoslayable del análisis.

Una vez precisados estos puntos, podemos sostener una de nuestras hipótesis: toda combinación de recursos léxico-gramaticales y discursivos adquiere 
el estatuto de estrategia discursiva cuando es puesto en correlación con un determinado propósito comunicacional y con una determinada conflictividad que ofrece una resistencia a su realización. Los recursos se constituyen así en el medio que pretende salvar la conflictividad y alcanzar el propósito identificado.

La orientación conflictiva de la estrategia satura la dimensión propositiva y material de la estrategia. Así, la existencia de una conflictividad —y esto se hará patente en las homilías - sugiere que una estrategia se puede encontrar tensionada por los propósitos que orientan a su realización de un modo diferente o, sencillamente, a su no realización. De la misma manera, dicha conflictividad o tensión dejará marcas en los recursos de la estrategia, de modo que la idea de coordinación coherente de los mismos requiere ser relativizada, para no imponerle al discurso mayor coherencia de la que él mismo tiene.

\section{EL GÉNERO Y EL ANÁLISIS DE LAS ESTRATEGIAS DISCURSIVAS: LAS CONFLICTIVIDADES GENÉRICAS}

En su obra Genre Relation. Mapping Culture (2008), Martin y Rose proponen la siguiente definición de género:

we characterised genres as staged, goal oriented social processes. Staged, because it usually takes us more than one step to reach our goals; goal oriented because we feel frustrated if we don't accomplish the final steps (...); social because writers shape their texts for readers of particular kinds. (2008:5)

Los autores reconocen a la misma como una definición de trabajo, un punto de partida para poder luego ampliar y precisar la noción. Nosotros la retomaremos con una finalidad semejante. De esta manera identificaremos en la formulación sus rasgos constitutivos para luego desarrollarlos y orientar la exposición. Desde nuestro punto de vista, es posible identificar, en la definición de Martin y Rose, tres aspectos constitutivos del género: a) su carácter de proceso social; b) su orientación hacia un determinado propósito o meta; y c) su organización en etapas. 
En el marco de esta concepción del género, las estrategias discursivas identificadas en las homilías católicas admiten una triple inscripción en el mismo: en el proceso social, en la finalidad (genérica), en las etapas. Esto significa que cada una de estas instancias de inscripción constituye una fuente de conflictividad estratégica, es decir, todas ellas conforman posibles aspectos de tensión que necesitan ser considerados al momento de elaborar un discurso explicativo de las estrategias.

A la vez, cada una de esas instancias de inscripción y conflictividad puede pensarse como una particular especificación de la conflictividad mayor que hemos postulado como dominante en el discurso homilético: la tensión entre adecuación y autorización. Las estrategias presentes en las homilías se encuentran, entonces, atravesadas por las tensiones propias del género como proceso social, del género como práctica orientada a un fin o meta, y del género como estructura esquemática (Eggins, 2004).

El género como proceso social inscribe a las estrategias en las problemáticas específicas del campo religioso, en general, y del católico, en particular. Aquí se actualizan las tensiones surgidas entre la escisión fundante entre aquellos agentes que mantienen una relación práctica y de consumo con los bienes religiosos y aquellos encargados de la producción y la reproducción de tales bienes (Bourdieu, 2009). Pero también corresponde aquí considerar aquellas complejizaciones a estos planteos derivadas de los procesos de secularización, las nuevas formas de religiosidad, etcétera, a las que deberemos recurrir para explicar un fenómeno particular que se produce en nuestro corpus.

Con relación al género como práctica orientada a un fin o meta, identificamos que la finalidad del género homilético es la puesta en relación del texto bíblico con las circunstancias en las cuales se produce la práctica discursiva concreta. Hemos utilizado también el término "actualización", presente en algunos autores (en especial, Arnoux y Blanco, 2002), con los reparos que demanda su origen confesional (es un término presente en tratados homiléticos producidos por la misma institución católica). La idea de puesta en relación supone, como sugiere la misma noción de género que estamos trabajando, diferentes pasos o instancias que la conforman y permiten su realización: la recuperación de ese texto, su exégesis, su aplicación y, por último, la intervención a través de directivas concretas.

Finalmente, el género como estructura esquemática nos introduce en las cuestiones específicas que adquiere la macrotensión adecuación-autorización en cada 
una de las etapas genéricas. Esto implica, para nosotros, que parte del estudio de este género consiste en la tipificación de las conflictividades inherentes a cada una de sus partes. En tanto se vuelve la más relevante para el estudio que aquí presentaremos, podemos detenernos en la etapa de paráfrasis. Esta etapa realiza, por una parte, su aporte a la finalidad del género — la de relacionar la homilía con las lecturas rituales y la de construir los insumos para las etapas posteriores de contextualización en el relato bíblico y aplicación-; pero, por otra, puede ser puesta en relación con la problemática específica de toda reformulación. En este sentido, la adecuación y la autorización de la etapa se juegan en la consideración del "umbral de distorsión" (Fuchs, 1994), en tanto límite que enfrenta toda reformulación y más allá del cual el destinatario no puede reconstruir la relación entre el texto reformulado y el texto reformulante. En principio, podríamos decir que la adecuación tensiona la paráfrasis hacia un registro más próximo a los destinatarios, y la autorización hacia una mayor proximidad con el texto fuente; sin embargo, como veremos en este artículo, esto se transforma y complejiza cuando lo que está en juego es el mismo acto de enunciación de la referencia bíblica.

\section{EL ANÁLISIS DE LAS ESTRATEGIAS EN LAS HOMILÍAS}

A continuación presentaremos el análisis de un grupo de estrategias que consideramos como el más recurrente en nuestro corpus, y que coincide con aquel en que se vuelve relevante la tensión constitutiva del género homilético. Las homilías se encuentran atravesadas por esos dos grandes polos de tensión que conforman la autorización y la adecuación. Las estrategias resultantes de la actividad analítica serán presentadas como las muestras materiales de esa tensión. Al decir de Foucault, las estrategias serán entendidas como esos "espacios de disensión" (2001 [1969]:257) y su análisis como la explicitación del encuentro de esas fuerzas y del modo en que los recursos lingüístico-discursivos las manifiestan. Este aspecto diferencia al análisis estratégico del mero relevamiento de rasgos lingüístico-discursivos que podrían distribuirse en esos polos. La estrategia discursiva, como categoría analítica, reúne algunos de esos rasgos alrededor de un propósito comunicacional y una conflictividad. Sin embargo, 
esta reunión no es estable ni está exenta de conflictos. Los rasgos, los recursos que reúne una estrategia, no se encuentran coordinados en relación a un fin, el cual explicaría las razones para la elección de cada uno de ellos. En esta última concepción, la estrategia se volvería "el texto ideal, continuo y sin asperezas, que corre bajo la multiplicidad de las contradicciones y las resuelve en la unidad serena de un pensamiento coherente" (Foucault, [1969] 2001: 262). El analista no pretende, a través de la noción de estrategia, presentar una resolución; pero tampoco cancela el hecho de que si las tensiones se muestran se debe a que las mismas ofrecen alguna suerte de resistencia a la realización de alguna finalidad interaccional. Toda homilía, en este sentido, vuelve a desafiar, una vez más, ese espacio conflictivo y el resultado de ese desafío son las estrategias discursivas.

\section{LA SELECCIÓN DE UNA CLASE DE ESTRATEGIAS: ESTRATEGIAS DE PARTICIPACIÓN E INTERACCIÓN CLAUSAL DEL TEXTO BÍBLICO}

Para el desarrollo de nuestra investigación seleccionamos un grupo de estrategias relevadas en nuestro corpus. Como puede preverse, el análisis en profundidad de todos los discursos, incluso estableciendo parámetros derivados de la hipótesis, redundaría en un producto demasiado extenso y difícil de aprehender. Por tal motivo hemos preferido abordar aquel grupo de estrategias que consideramos relevantes dentro del conjunto $y$, a la vez, significativas para la verificación de la hipótesis postulada en la investigación.

De un modo general, las estrategias que analizamos en nuestra investigación se pueden agrupar bajo la formulación estrategias de participación e interacción clausal del texto bíblico. Bajo este rótulo ingresa el análisis de aquellas cláusulas que tienen al texto bíblico como agente, objeto o circunstancia. Dentro del conjunto propondremos una segunda distinción: 1) Los modos de agentivación del texto bíblico; 2) Los modos de objetivación del texto bíblico. El primer grupo reúne las cláusulas en las que el texto bíblico ocupa el rol de agente del proceso representado; y el segundo grupo, por su parte, lo conforman las cláusulas en las que el texto participa como objeto o circunstancia. 
Esta selección debe relacionarse con el papel relevante que ocupa el texto bíblico en la totalidad del género homilético. La homilía se constituye, en principio, a partir de las dos o tres lecturas que preceden a la palabra del sacerdote, y no avanza ni alcanza a producir un nuevo y diferente discurso si no es a partir de esos fragmentos bíblicos. La homilía responde al "comentario" (Foucault, 1992 [1970]:21 y ss.) y a su doble cometido: el de producir infinidad de nuevos discursos a partir de ese discurso primero, separado y diferente; y el de negar la novedad de esos discursos para presentarlos como un mero "volver a decir" lo que ya el texto prefiguraba. Al analizar las estrategias discursivas que operan sobre el texto bíblico, que lo asedian, que lo hacen hablar, que le otorgan un lugar, un tiempo, un comportamiento, buscamos, de alguna manera, estudiar los diferentes modos en que las homilías articulan, en la materialidad discursiva, esta relación de productividad.

Pero la relación de la homilía con ese texto bíblico que le permite surgir y del que se presenta como una mera realización se inscribe, a su vez, en la complejidad y la conflictividad de la práctica religiosa. En efecto, la relación entre estos elementos recuerda las observaciones de Durkheim (1991 [1912]) acerca del vínculo entre los seres sagrados y el culto positivo. Los seres sagrados, como el texto bíblico, están, por definición, "sustraídos a los alcances profanos"; sin embargo, "no servirían de nada y carecerían de toda razón de ser si no fueran puestos en relación con esos mismos fieles que, por otra parte, deben permanecer respetuosamente alejados de ellos" (1991 [1912]:460). En este sentido, al igual que los ritos positivos, toda homilía constituye "un verdadero sacrilegio". Pero lo que importa, en última instancia, dirá Durkheim, son las precauciones con las que ese sacrilegio se lleva a cabo. Al estudiar las estrategias de participación e interacción clausal del texto bíblico nos interesa mostrar los modos en que ese sacrilegio se realiza, se exhibe, se atenúa o se oculta en las homilías católicas estudiadas. 


\section{LOS GRUPOS DE ESTRATEGIAS Y LA IDENTIFICACIÓN DE LOS RECURSOS}

Por razones de espacio, en este trabajo sólo presentaremos el análisis del primer grupo de estrategias — modos de agentivación del texto bíblico- en el conjunto de homilías registradas en la iglesia Nuestra Señora del Carmen. Las estrategias serán identificadas en aquellas cláusulas en las cuales, como señalamos, el texto bíblico ocupa el lugar de actor o agente en el sistema de transitividad (Halliday, 1994 [1985]). Este primer criterio permite conformar un grupo significativo y sustancial de pasajes dentro del corpus, un número relevante de cláusulas distribuidas de un modo relativamente homogéneo dentro de los diferentes grupos de homilías que se constituyen alrededor de las iglesias en las que se realizaron los registros.

Sobre este primer grupo hemos decidido establecer, a su vez, una segunda distinción. Por una parte, es posible analizar aquellas cláusulas que, teniendo al texto bíblico como agente, se organizan alrededor del proceso verbal "decir"; por otra parte, todas aquellas con procesos diferentes, es decir, relacionales, existenciales, materiales, comportamentales y mentales. Para el desarrollo de este artículo nos focalizaremos sólo en el primero de estos grupos.

Corresponde explicitar aquí una segunda decisión metodológica para la selección de las cláusulas a analizar. En el marco de la Gramática SistémicoFuncional, el participante Emisor de los procesos verbales es, por lo general, un humano. Sin embargo, como señalan Halliday (1994 [1985]:140) y Thompson (2004:101), el mensaje también puede ser representado como transmitido por otra clase de emisores ${ }^{3}$ que adquieren, así, un carácter antropomórfico. Esta observación es relevante para nosotros porque es la que nos permite agrupar en la categoría "texto bíblico" a emisores como "Jesús", "el evangelista", "el

\footnotetext{
${ }^{3}$ Dice Halliday: "It follows (...) that, unlike mental process, verbal processes do not require a conscious participant. The Sayer can be anything that puts out a signal (...) a Sayer can just as readily be it as he or she. For this reason verbal process might more appropriately be called 'symbolic' process" (1994 [1985]:140; destacado en el original). Thompson, por su parte, señala: "There is one participant that is involved in any verbal process: this is the Sayer. Typically, of course, the Sayer is human, but messages can be represented as conveyed by other types of Sayer as well: One report says a man was seen running from the house son after the shooting" (2004:101).
} 
Señor", "el Evangelio", entre otros. Sabemos que la atención a las diferencias entre estos elementos nos permitiría señalar mayores matices en la agentividad de las cláusulas con procesos verbales, no obstante también consideramos que la decisión operativa del agrupamiento de estos "emisores" ofrece una primera información relevante acerca de los modos de tratamiento discursivo del decir del texto bíblico en las homilías.

Lo anterior no niega que, por su carácter esperable y recurrente, el análisis de este primer grupo de cláusulas - las del decir - tenga un significativo grado de detalle. Sin embargo, es necesario aclarar que la focalización estará puesta, principalmente, en los modos de realización de los significados ideativos e interpersonales, relegando el nivel textual para pasajes puntuales. Es por esto que en este primer grupo de cláusulas atenderemos a: a) los modos de inscripción del participante Destinatario; b) modos de ocurrencia del verbo "decir"; c) las formas de la locución en las cláusulas del decir. Los aspectos permiten conformar los conjuntos de recursos que se consideran más relevantes en las estrategias de agentivación verbal del texto bíblico y establecer parámetros de comparación entre las estrategias de las homilías de las diferentes iglesias estudiadas.

\section{LA ORGANIZACIÓN DE LOS RECURSOS SEGÚN LA TENSIÓN IDENTIFICADA}

El análisis y la organización de los recursos que conforman las estrategias estudiadas se corresponden con una serie de posicionamientos teóricos y metodológicos que llevamos adelante en esta investigación. Uno de ellos establece que las estrategias se conciben como una combinación de recursos. Los recursos, a su vez, son entendidos como las opciones realizadas de manera efectiva en el conjunto de discursos que conforman nuestro corpus (Menéndez, 2006:14). Sin embargo, en cada uno de los discursos que conforman nuestro corpus se actualiza un número altísimo de las opciones y no por ello las hemos considerado a todas como recursos ni las hemos tomado a todas como objeto de análisis. Esto significa que junto con la diferenciación entre opción y recurso es necesario incorporar cuál es el criterio con el que se seleccionan 
ciertos recursos y se relegan otros. Este criterio lo conforma, en nuestra investigación, la funcionalidad que adquieren tales recursos en el marco de las dos grandes clases de estrategias que hemos enunciado en el apartado anterior: los modos de agentivación del texto bíblico y los modos de objetivación del texto bíblico. De todas las opciones realizadas en los discursos, se visibilizan y seleccionan sólo aquellas combinaciones que colaboran a la realización de la finalidad atribuida a la estrategia discursiva.

Inscriptos en una perspectiva analítica estratégica, los recursos son susceptibles de nuevas organizaciones y filiaciones. Desde nuestro punto de vista, el criterio para estas nuevas agrupaciones lo establece el tercer componente que hemos reconocido en nuestra definición de estrategia: la conflictividad. Si los recursos pueden aproximarse - de un modo gradual- y filiarse o, por el contrario, distanciarse y oponerse, es porque ellos pueden ser puestos en relación con una determinada conflictividad que tensa la génesis misma del despliegue estratégico-discursivo. En el caso de las estrategias que analizaremos en este trabajo, la principal conflictividad que las recorre es la tensión entre los efectos de opacidad y de transparencia sobre el texto bíblico. En efecto, ambas clases de estrategias — sea que lo agentiven o que lo objetiven-implican cierta construcción de un estatuto enunciativo del texto bíblico: o se refuerza su carácter críptico, oscuro, demandante de la actividad especializada; o se lo representa como accesible, evidente, disponible sin mayores dificultades para todos. Opacidad y transparencia conforman así un continuum en el que pueden disponerse los diferentes recursos, en el que pueden organizarse según el modo en que participan de la conflictividad estratégica que atraviesa el mismo discurso, según la forma en que sus efectos son atraídos por cada uno de los polos.

\section{LA AGENTIVACIÓN VERBAL DEL TEXTO BÍBLICO: LOS MODOS DE INSCRIPCIÓN DEL DESTINATARIO EN EL PROCESO VERBAL}

El análisis del corpus permite dar cuenta de diferentes modos de realización del Destinatario en las cláusulas con proceso verbal. Estas posibilidades pueden ser analizadas en clave de los efectos graduales de transparencia/opacidad que permi- 
ten a las estrategias. Así, en tanto la transparencia supone la mera mostración de la locución del texto bíblico, la ausencia de Destinatario en la cláusula parece ser el recurso que más aproxima el discurso a este polo. Veamos un primer caso tomado del segundo registro realizado en la iglesia Nuestra Señora del Carmen (DC-2):

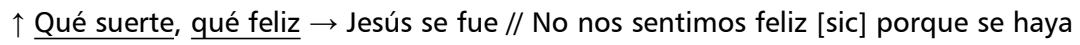
ido / $\uparrow$ sino porque adónde se fue y por qué se fue / Es la gloria de Cristo // [ac] Si tanto nos dolió su vida en la tierra / [le] su pasión sobre todo / el hecho de que nos dejara para ir a::: / tomar posesión del reino / es un motivo de alegría $\uparrow$ Y por eso los apóstoles se sintieron felices // Ésta es la fiesta de la ascensión /// cuarenta días después de Pascua / $\uparrow$ Qué fiestas de alegría $\rightarrow$ son los años litúrgicos $\uparrow$ Volvieron $\rightarrow$ dice / hoy / el Evangelio, [le.] llenos de gran alegría. (DC-2, [002-009]) ${ }^{4}$

\begin{tabular}{|l|l|}
\hline 1 & Qué suerte, \\
\hline 2 & qué feliz \\
\hline 3 & Jesús se fue \\
\hline 4 & No nos sentimos feliz [sic] \\
\hline & porque \\
\hline 5 & se haya ido \\
\hline & sino \\
\hline 6 & porque \\
\hline & adónde se fue \\
\hline 7 & por qué se fue \\
\hline 8 & Es la gloria de Cristo \\
\hline & Si \\
\hline 9 & tanto nos dolió su vida en la tierra, su pasión sobre todo \\
\hline 10 & el hecho de (12) es un motivo de alegría. \\
\hline 12 & que nos dejara \\
\hline & para \\
\hline 13 & ir a tomar posesión del reino \\
\hline & Y \\
\hline & por eso \\
\hline
\end{tabular}

(continúa en la página siguiente)

\footnotetext{
${ }^{4}$ Ver "Convenciones utilizadas para la transcripción" al final del artículo.
} 


\begin{tabular}{|l|l|}
\hline 14 & los apóstoles se sintieron felices. \\
\hline 15 & Ésta es la fiesta de la ascensión cuarenta días después de Pascua. \\
\hline 16 & Qué fiestas de alegría son los años litúrgicos. \\
\hline 17 & $(18)$ dice hoy el Evangelio (18). \\
\hline 18 & $\backslash<>$ Volvieron (17) llenos de gran alegría $\backslash$ \\
\hline
\end{tabular}

Nos interesan las cláusulas 17 y su proyectada, la 18, cláusulas en la que encontramos el proceso verbal "decir":

\begin{tabular}{|l|l|l|l|l|}
\hline LOCUCIÓN & PROCESO VERBAL & CIRCUNSTANCIA & EMISOR & LOCUCIÓN \\
\hline [los apóstoles] Volvieron, & dice & hoy & el Evangelio, & llenos de gran alegría \\
\hline
\end{tabular}

Al momento de considerar los casos de inclusión del Destinatario, reconocemos que la mayoría de los autores (Halliday, 1994 [1985]; Thompson, 2004; Fernández y Ghio, 2005) coinciden en la semejanza que puede establecerse entre el participante Destinatario del proceso verbal y el Beneficiario del proceso material, entendido este último como un participante que es beneficiado por la realización del proceso. Para Martin (Martin, Matthiessen y Painter, 1997:114), estas semejanzas abren un espacio para las escalas o clines entre el decir (proceso verbal) y el hacer u ocurrir (procesos materiales). La similitud entre Destinatario y Beneficiario acentúa el aspecto "comportamental" del proceso verbal, esto es, el decir como actividad.

En nuestro corpus y en este grupo de homilías en particular, la inclusión del Destinatario, por su parte, se desdobla en dos operaciones: la selección del nosotros inclusivo y la selección de personajes pertenecientes al mismo relato bíblico. ${ }^{5}$ Un ejemplo del primer caso sería:

Y el Espíritu Santo / $\downarrow$ los transformó /// $\uparrow$ realmente / $\rightarrow$ qué cambio admirable /// $\uparrow$ [ac.] nos narran los Hechos de los Apóstoles cómo en ese mismo día salió a la calle Pedro / qué miedos ni qué ahora // $\downarrow$ va a tener dificultad / $\uparrow$ [ac.] Salió a la calle en Jerusalén y empezó a predicarle a este Cristo que ustedes mataron /// $\downarrow$ [le.] Convirtió a tres mil / bautizó ese mismo día // nos dice el evangelista. (DC-3, [021-025])

${ }^{5}$ Aludidos a través de las formas nominales tomadas del texto bíblico y formas pronominales de tercera persona. 


\begin{tabular}{|l|l|}
\hline & Y \\
\hline 1 & el Espíritu Santo los transformó realmente \\
\hline 2 & qué cambio admirable \\
\hline 3 & nos narran los Hechos de los Apóstoles \\
\hline 4 & cómo en ese mismo día salió a la calle Pedro \\
\hline 5 & qué miedos \\
\hline & ni \\
\hline 6 & qué ahora va a tener dificultad \\
\hline 7 & Salió a la calle en Jerusalén \\
\hline & y \\
\hline 8 & empezó a predicarle a este Cristo (9) \\
\hline 9 & que ustedes mataron \\
\hline 10 & (11) (12) nos dice el evangelista. \\
\hline 11 & Convirtió a tres mil \\
\hline 12 & bautizó ese mismo día \\
\hline
\end{tabular}

Si nos detenemos en la cláusula 10 -aquella en donde se presenta el proceso verbal "decir" que estamos estudiando- y las proyectadas 11 y 12 ,

Convirtió a tres mil bautizó ese mismo día nos dice el evangelista. (DC-3, [025])

podemos hacer el siguiente análisis de sus componentes funcionales:

\begin{tabular}{|l|l|l|l|}
\hline LOCUCIÓN & DESTINATARIO & PROCESO VERBAL & EMISOR \\
\hline \Convirtió a tres mil \ $\backslash$ bautizó ese mismo día & nos & dice & el evangelista. \\
\hline
\end{tabular}

En la cláusula 10, la atribución de la función de Destinatario al pronombre de la primera persona del plural construye una representación en la cual los fieles son incorporados como los beneficiarios de las palabras del "evangelista" -Emisor del discurso referido-. De este modo, se acentúan los aspectos comportamentales e interpeladores del proceso verbal y se genera un efecto de menor transparencia sobre el texto bíblico.

Si consideramos ahora aquellos casos en los que la inclusión del Destinatario se realiza a por medio de la selección de personajes pertenecientes al relato bíblico, podemos tomar el siguiente pasaje: 
$\uparrow$ Cristo cabeza $\rightarrow$ lo veíamos el domingo pasado / ya ascendió a los cielos / $\uparrow$ [ac.] pero como subió la cabeza tiene que subir el cuerpo // [ac.] y el cuerpo no está muerto / tiene alma $/ / \rightarrow$ [le.] y ese espíritu del alma de toda la Iglesia es el Espíritu Santo $/ \uparrow[\mathrm{ac}]$ a quien Cristo le encomendó la Iglesia / $\rightarrow$ después que él ascendió a los cielos // [le.] por eso [Jesús] les dice / id y enseñad a toda la gente // con el fervor de la palabra, $\uparrow$ con el testimonio de sus vidas / con la sangre con que marcaron $\rightarrow$ [le.] el vigor de lo que predicaban. (DC-3, [040-046])

\begin{tabular}{|l|l|}
\hline 1 & Cristo, cabeza, (2), ya ascendió a los cielos \\
\hline 2 & lo veíamos el domingo pasado \\
\hline & pero \\
\hline & como \\
\hline 3 & subió la cabeza \\
\hline 4 & tiene que subir el cuerpo \\
\hline 5 & y \\
\hline 6 & $<>$ tiene alma \\
\hline & y \\
\hline 7 & ese espíritu del alma de toda la Iglesia es el Espíritu Santo (8) \\
\hline 8 & a quien Cristo le encomendó la Iglesia \\
\hline & después que \\
\hline 9 & él ascendió a los cielos \\
\hline & por eso \\
\hline 10 & $<>$ [Jesús] les dice (11) \\
\hline 11 & id \\
\hline & y \\
\hline 12 & \begin{tabular}{l} 
enseñad a toda la gente, con el fervor de la palabra, \\
\hline
\end{tabular} \\
\hline 13 & que marcaron el vigor de (14) \\
\hline 14 & lo que predicaban \\
\hline
\end{tabular}

En tanto se organizan a partir del proceso verbal "decir", nos interesan las cláusulas 10, 11 y 12 (estas dos últimas proyectadas por el proceso verbal), y las incrustadas 13 y 14. 
[Jesús] les dice / id y enseñad a toda la gente // con el fervor de la palabra, $\uparrow$ con el testimonio de sus vidas / con la sangre con que marcaron $\rightarrow$ [le.] el vigor de lo que predicaban. (DC-3, [045-046])

\begin{tabular}{|l|l|l|l|l|}
\hline CONECTOR & EMISOR & DESTINATARIO & PROCESO VERBAL & LOCUCIÓN \\
\hline por eso & [Jesús] & les [a los apóstoles] & dice & $\begin{array}{l}\text { lid y lenseñad a toda la gente } \\
\text { con el fervor de la palabra, con } \\
\text { el testimonio de sus vidas, con la } \\
\text { sangre con <que marcaron el vigor } \\
\text { de }<\text { lo que predicaban }>l .\end{array}$ \\
\hline
\end{tabular}

La selección, para el proceso verbal ("dice"), de un Destinatario interno, es decir, de personajes tomados del relato bíblico ("les [a los apóstoles]"), supone una aproximación del discurso homilético al texto sagrado. A la vez, y como contrapartida, este recurso genera un distanciamiento entre la representación clausal y el evento comunicacional que constituye la homilía, del que participan el sacerdote y los fieles. De esta manera, la cláusula no se limita a decir, como ocurre con la omisión del Destinatario, tampoco involucra a los fieles a través del nosotros inclusivo como destinatario del decir. La cláusula utiliza un proceso verbal para representar un acontecimiento del cual los participantes del evento comunicativo están excluidos y los únicos involucrados son los mismos personajes del texto que es reformulado. Con este recurso, aumenta el grado de extrañamiento, distancia y opacidad del texto, el cual es devuelto a sus condiciones de producción, a la situación enunciativa conformada por el texto fuente. El texto bíblico se vuelve así un objeto extraño, autorreferencial, que requiere una actividad exegética, que es la llevada a cabo por el sacerdote.

En suma, el análisis de las cláusulas de este grupo de homilías permite reconocer tres modos de inscripción del participante Destinatario: la omisión, la selección del nosotros inclusivo y la inclusión de personajes pertenecientes al texto bíblico. Como hemos anticipado, estos recursos pueden ubicarse en la gradiente que establece los grados de opacidad y la transparencia con que es representado el texto bíblico. En este sentido, la omisión genera un efecto de transparencia y mostración del decir, el cual, al no seleccionar ningún beneficiario, es meramente exhibido por el discurso homilético. La selección del 
nosotros inclusivo, en cambio, le otorga al texto bíblico una capacidad para intervenir sobre la misma interacción comunicacional e interpelar a los fieles, para involucrarlos en la representación del decir bíblico. Por último, la inclusión como destinatarios a personajes pertenecientes al texto bíblico deja afuera a los participantes de la interacción, construye una representación en donde el texto refuerza su autorreferencialidad y, por ende, su carácter opaco y complejo.

\begin{tabular}{|l|l|l|}
\hline IGLESIA DEL CARMEN & \multicolumn{2}{|l|}{ INSCRIPCIÓN DEL PARTICIPANTE } \\
DESTINATARIO EN EL PROCESO VERBAL
\end{tabular}

\section{LA AGENTIVACIÓN VERBAL DEL TEXTO BÍBLICO: LOS MODOS DE OCURRENCIA DEL VERBO “DECIR"}

Junto con los modos de realización del participante Destinatario en la cláusula, corresponde atender a los modos de ocurrencia del verbo conjugado en cada cláusula con proceso verbal, lo que supone considerar no sólo los significados ideativos, sino también los interpersonales que se construyen en las estrategias. En los casos trabajados en el punto anterior los verbos conjugados se encontraban en presente. Este rasgo tiene una alta frecuencia en este grupo de homilías y puede leerse como parte del proceso de actualización del texto bíblico. En el marco de la Gramática Sistémico-Funcional, el tiempo del discurso es uno de los componentes, junto con la modalidad, del elemento Finito. En términos de Halliday: 
The Finite element, as its name implies, has the function of making the proposition finite. That is to say, it circumbribes it; it brings the proposition down to earth, so that it is something that can be argued about. A good way to make something arguable is to give it a point of reference in here and now; and this is what the Finite does, it relates the proposition to its context in the speech event. (1994 [1985]:75)

Para nuestro análisis, esto significa, en parte, que el estudio del tiempo de los procesos verbales nos permite dar cuenta de la manera en que las cláusulas inscriben al texto bíblico en la interacción comunicacional que se construye durante la homilía. El tiempo dado al proceso verbal de las cláusulas que estamos analizando construye el carácter más o menos vigente o contemporáneo del texto bíblico. Esto es lo que nos permitía inferir que el uso del tiempo presente colaboraba al efecto de actualización del texto bíblico.

De este modo, el tiempo y la modalidad pueden funcionar como indicadores del grado de transparencia u opacidad que se le otorga al texto bíblico. En efecto, mientras el tiempo presente aumenta la mostración, la vigencia, la posibilidad de discutir y polemizar ${ }^{6}$ acerca de ese discurso referido, el tiempo pasado sugiere su distancia de la interacción verbal, postula una representación del texto bíblico como algo que necesita ser escrutado, interpretado para volverse significativo, para volverse vigente. Aquí algunos ejemplos:

$\uparrow$ Y el mismo $\rightarrow$ Jesús nos decía /// sean misericordiosos // sean perfectos // como lo es / el Padre del cielo. (DC-1, [059-060])

[le.] Y así / saber que // el mismo Jesús, [ac.] como nos decía [le.] en el último versículo de este evangelio // $\uparrow$ así como ustedes // juzgan, $\rightarrow$ serán conde...- juzgados, [ac.] así como ustedes condenan, $\downarrow$ serán condenados, [le.] $\rightarrow$ y sepan que con la misma medida / que ustedes miden / $\downarrow$ serán medidos. (DC-1, [106-110])

\footnotetext{
${ }^{6}$ Dice Halliday: "A proposition may become arguable by having its relevance to the speech event specified in these temporal terms" (1994 [1985]:75).
} 
San Pablo dice que tenemos que predicar a Cristo [le.] oportuna e inoportunamente. (DC-2, [152-153])

[le.] Por eso [Jesús] les dice / id y enseñad a toda la gente // con el fervor de la palabra, $\uparrow$ con el testimonio de sus vidas / con la sangre con que marcaron $\rightarrow$ [le.] el vigor de lo que predicaban. (DC-3, [044-046])

$\uparrow$ [ac.] Salió a la calle y Jerusalén y empezó a predicarle a este Cristo que ustedes mataron /// $\downarrow$ [le.] Convirtió a tres mil / bautizó ese mismo día // nos dice el evangelista. (DC-3, [023-025])

En definitiva, puede sugerirse que la diferencia temporal entre presente y pasado del proceso verbal ofrece un nuevo recurso gramatical para la construcción de la mayor o menor opacidad del texto bíblico, la cual, a su vez, puede combinarse con el recurso relativo al modo de realización del participante Destinatario. De esta manera las estrategias pueden dar cuenta de matices y graduales desplazamientos en el continuum, surgidos de las combinaciones entre el recurso relativo a los diferentes modos de incorporación del participante y el tiempo pasado / presente de verbo conjugado.

Por último digamos que, desde otra perspectiva, la distinción de estos recursos nos permite dar cuenta de las tensiones que pueden atravesar a la cláusula y a la homilía toda. La combinación de los recursos manifiesta, en este sentido, menos una coorientación para la realización del propósito comunicacional, que la marca indicativa de la no resolución ni atenuación de las fuerzas que atraviesan el discurso homilético. Así, mientras el recurso del nosotros inclusivo como participante Destinatario puede orientarse hacia el polo de la transparencia (y diferenciarse de la autorreferencialidad), el tiempo pasado del proceso verbal tiende hacia el polo de la opacidad, en tanto refuerza el distanciamiento del texto del presente de la enunciación ("Y el mismo Jesús nos decía sean misericordiosos..."). En relación con esto último, cabe destacar que no encontramos en este grupo de homilías ningún caso de combinación de la ausencia del participante Destinatario y el verbo conjugado en tiempo pasado. 


\begin{tabular}{|l|l|l|}
\hline IGLESIA DEL CARMEN & \multicolumn{2}{|c|}{ EL TIEMPO DEL VERBO CONJUGADO } \\
\hline $\begin{array}{l}\text { Y el mismo Jesús nos decía sean misericordiosos, sean } \\
\text { perfectos, como lo es el Padre del cielo. (DC-1, [059-060]) }\end{array}$ & decía & opacidad \\
\hline $\begin{array}{l}\text { Volvieron, dice hoy el Evangelio, llenos de gran alegría. } \\
\text { (DC-2, [008-009]) }\end{array}$ & dice & transparencia \\
\hline
\end{tabular}

\section{LA AGENTIVACIÓN VEBAL DEL TEXTO BíBLICO: LAS FORMAS DE LA LOCUCIÓN EN TANTO OBJETO DEL PROCESO VERBAL}

Los modos en que es referido el decir bíblico también permiten desplegar un nuevo conjunto de recursos que colaboran a la construcción de efectos de opacidad y transparencia en las estrategias discursivas. De un modo general y a los fines de agrupar estas variedades, propondremos considerar tres grandes clases de referencia: 1) el estilo directo; 2) el estilo indirecto; 3 ) el verbiage o informe. ${ }^{7}$

Somos conscientes de que la conformación de este repertorio de recursos equipara elementos que para la Gramática Sistémico-Funcional no pertenecen a rangos semejantes. Los dos primeros casos - "estilo directo" (quote) y "estilo indirecto" (report) — son producto de la capacidad que tienen los procesos verbales de proyectar una cláusula y conformar así un complejo de cláusulas. Mientras que el denominado "estilo directo" consiste en una proyección de tipo paratáctica, el "indirecto" lo es de tipo hipotáctica. Ambos constituyen "aquello que es dicho" ("what is said", Halliday, 1994 [1985]:140) en el proceso verbal y dan cuenta, en términos de Thompson (2004:210), de una "representación de una representación (lingüística)", y no de una representación de una "experiencia (no lingüística)". 8

\footnotetext{
${ }^{7}$ El término alternativo de "informe" para el inglés verbiage es propuesto por Fernández y Ghio (2005:97).

8 "We use language to talk about phenomena in the world; but one group of phenomena that can be talked about is stretches of language. If we include in our message the wording or the meaning of original language event, we are not directly representing '(non-linguistic) experience' but giving our 'representation of a (linguistic) representation'" (Thomspon, 2004:210).
} 
El informe o verbiage, por el contrario, no consiste en una proyección, sino en un cambio de rango, y forma parte de los posibles participantes del proceso verbal. El informe puede presentar a) el contenido de lo que es dicho o b) el acto de habla y la lengua misma en la que se realiza la representación (Halliday, 1994 [1985]:141).

Aunque constituye una recuperación flexible de las nociones gramaticales para conformar los grupos de recursos, la inclusión de estas posibilidades nos permite organizar de mejor manera los grados de transformación lingüística y de reflexión metalingüística que realizan las alusiones al texto bíblico. En el marco del presente análisis, este repertorio de opciones puede ser dispuesto, entonces, en el continuum en el que estamos organizando el resto de los recursos. De esta manera, es posible reconocer que el estilo directo, en tanto presenta al decir referido como no modificado ni alterado por la referencia, sino citado de un modo literal (o construyendo un efecto de literalidad), correspondería al polo de la transparencia, en tanto atenúa la relación mediada con el texto y colabora, tal como hemos visto en otros recursos, a la mostración de la palabra bíblica. Tal es lo que podemos ver en el siguiente pasaje:

[le.] Como me persiguieron a mí / os perseguirán a vosotros [apóstoles] // y seréis vosotros también perseguidos, $\downarrow$ les decía Cristo. (DC-2, [029-031])

\begin{tabular}{|l|l|}
\hline & Como \\
\hline 1 & $\backslash$ me persiguieron a mí \} $\\
{\hline 2} &{\backslash \text { os perseguirán a vosotros \} } \\
{\hline} &{y} \\
{\hline 3} &{\backslash \text { seréis vosotros también perseguidos \} } \\
{\hline}\end{array}$
\end{tabular}

\begin{tabular}{|l|l|l|l|}
\hline LOCUCIÓN & DESTINATARIO & PROCESO VERBAL & EMISOR \\
\hline $\begin{array}{l}\text { Como } \backslash \text { me persiguieron a mí } \backslash \backslash \text { os per- } \\
\text { seguirán a vosotros } \backslash y \backslash \text { seréis vosotros } \\
\text { también perseguidos } \backslash\end{array}$ & les [a los apóstoles] & decía & $\begin{array}{l}\text { Cristo. } \\
\text { (DC-2, [029-031]) }\end{array}$ \\
\hline
\end{tabular}

Una de las principales características del estilo directo es la no modificación del sistema deíctico del discurso referido, algo que se reconoce en el pasaje que acabamos de citar. En este caso, la organización temporal de los verbos de la locución se dispone alrededor del presente ficcional construido por el relato bí- 
blico, lo que permite distribuir un pasado ("persiguieron", cláusula 1) y un futuro ("perseguirán" y "seréis", cláusulas 2 y 3, respectivamente) diferente al presente la enunciación (marcado en el elemento finito "decía" que introduce la cita). Otro tanto ocurre con la referencia de la segunda persona de estos verbos y el pronombre ("vosotros", cláusula 3) que no coincide con la audiencia de la homilía, sino con los destinatarios de la interacción discursiva del relato bíblico que es referido.

Respecto de este polo de transparencia y literalidad, el estilo indirecto y el informe se presentan como desplazamientos en donde se pone en evidencia la intervención del sacerdote sobre el texto referido. $Y$ una de las principales modificaciones que realiza el estilo indirecto consiste, justamente, en el reacomodamiento de la palabra referida al sistema deíctico del discurso que está realizando la referencia. De este modo, en el siguiente pasaje:

San Pablo dice <que tenemos que predicar a Cristo [le.] oportuna e inoportunamente- $>$. (DC-2, [152-153])

\begin{tabular}{|l|l|}
\hline 1 & San Pablo dice (2) \\
\hline 2 & que tenemos que (3) \\
\hline 3 & predicar a Cristo oportuna e inoportunamente \\
\hline
\end{tabular}

\begin{tabular}{|l|l|l|}
\hline EMISOR & PROCESO VERBAL & LOCUCIÓN \\
\hline San Pablo & dice & $\begin{array}{l}\text { que tenemos que } \backslash \text { predicar a Cristo oportuna } \\
\text { e inoportunamente. } \backslash(\text { DC-2, [152-153]) }\end{array}$ \\
\hline
\end{tabular}

La primera persona del plural en verbo modal de aspecto imperativo ("tenemos que predicar") puede constituirse en una forma inclusiva (yo + ustedes [los destinatarios de la homilía]) y su tiempo presente, incluso, puede volverse coincidente con el tiempo de la enunciación (marcado nuevamente en el proceso verbal ("dice").

La comparación entre ambos pasajes nos permite establecer la diferencia de estos estilos y sus efectos de mayor o menor opacidad sobre el texto. El segundo pasaje, a través del estilo indirecto, transforma al texto bíblico, lo interviene para volverlo capaz de interpelar a los presentes e involucrarlos en el proceso referido, en la prédica demandada ("tenemos que predicar"). En el primer pasaje, la persecución ("me persiguieron", "os perseguirán", "seréis perseguidos") es una 
acción puramente mostrada, y cualquier tipo de identificación e involucramiento es delegada a la actividad interpretativa de los fieles que escuchan la homilía.

En el grupo de homilías que estamos analizando, correspondientes a la iglesia Nuestra Señora del Carmen, la presencia de procesos verbales en estilo indirecto es muy reducida y casi ínfima. Este ejemplo, en particular, que constituye casi el único, muestra una combinación especial de recursos: aquellos relativos al participante Destinatario (no manifiesto en la cláusula), al modo de referir la locución (estilo indirecto) y a la utilización del nosotros inclusivo como sujeto gramatical del elemento Finito ("tenemos que predicar") presente en la cláusula proyectada. Sobre el final de este apartado relativo a los procesos verbales, nos detendremos en esta combinación de recursos que da cuenta de las tensiones que atraviesan el discurso y lo configuran como un espacio de conflicto.

La otra variante de presentación de la locución de un proceso verbal que nos interesa consignar en este apartado es el verbiage o informe. En este caso, el contenido del decir no se realiza a través de una cláusula proyectada sino a través de, por ejemplo, un grupo nominal:

el Señor // nos dice <todo [ac.] lo que tenemos que hacer> (DC-1, [007-008])

\begin{tabular}{|l|l|l|l|}
\hline EMISOR & DESTINACIÓN & PROCESO VERBAL & LOCUCIÓN \\
\hline El Señor & nos & dice & todo lo que tenemos que hacer. (DC-1, [007-008]) \\
\hline
\end{tabular}

Como ya anticipamos, en la distribución que estamos realizando de esta variedad de recursos, el informe parece ubicarse más próximo al polo de la opacidad, en la medida en que supone un procesamiento del decir bíblico y una elisión de todos aquellos aspectos que permitirían reconstruir la cláusula o las coordenadas enunciativas de la palabra referida. El informe presenta una lectura, una interpretación, una reformulación evaluativa capaz de reducir el texto bíblico a un grupo nominal que condensaría el sentido del texto primero.

En el caso que acabamos de citar, el análisis adquiere una complejidad extra debido a que el grupo nominal que constituye la locución se encuentra conformado por un adjetivo ("todo") y una cláusula incrustada ("lo que tenemos que hacer"). La combinación de estos dos elementos constituyentes del grupo nominal es la que va a orientar la lectura y la interpretación del texto bíblico. Una 
de estas orientaciones está en el carácter imperativo que permite introducir la cláusula incrustada por medio del verbo modal en el elemento Finito: "tenemos que hacer"; otra está dada, justamente, por el verbo auxiliado de la perífrasis que ubica la obligatoriedad en un ámbito particular de la experiencia: el hacer.

Esta reformulación evaluativa del texto bíblico no sólo orienta -anafóricamente- el modo de lectura del fragmento que ha precedido a la homilía, sino también las otras referencias - catafóricamente - presentes en el discurso del sacerdote, posteriores al informe que estamos analizando. Para ver esto es necesario inscribir la cláusula en un pasaje más amplio:

...el Señor // nos dice todo [ac.] lo que tenemos que hacer. $\uparrow$ Sobre todo /// eh // $\rightarrow$ pensando de que // el Evangelio de hoy es la continuación del domingo pasado. ¿ ise acuerdan el domingo pasado, que hablábamos de la bienaventuranza? Esto nos va a ayudar a vivir las bienaventuranzas que el domingo pasado escuchábamos. // Por eso, / eh // el Señor hoy nos muestra, de una forma concreta, vivir las bienaventuranzas. Se acuerdan que una de las bienaventuranzas decía: "felices aquellos que son insultados, aquellos que son perseguidos, aquellos que son maltratados, felices aquellos que lloran". Y hoy Jesús nos dice: "amen a sus enemigos". (DC-1, [007-015])

\begin{tabular}{|l|l|}
\hline 1 & el Señor nos dice (2) \\
\hline 2 & todo lo que tenemos que hacer \\
\hline 3 & Sobre todo... eh... pensando de (4) \\
\hline 4 & que el Evangelio de hoy es la continuación del domingo pasado \\
\hline 5 & iSe acuerdan el domingo pasado, \\
\hline 6 & que hablábamos de la bienaventuranza? \\
\hline 7 & Esto nos va a ayudar a (8) \\
\hline 8 & vivir las bienaventuranzas (9) \\
\hline 9 & que el domingo pasado escuchábamos \\
\hline 10 & Por eso, \\
\hline 11 & el Señor hoy nos muestra, de una forma concreta, (11) \\
\hline 12 & Se acuerdan (13) \\
\hline 13 & que una de las bienaventuranzas decía: \\
\hline 14 & "felices aquellos (14), aquellos (15), aquellos (16), felices aquellos (17)" \\
\hline
\end{tabular}




\begin{tabular}{|l|l|}
\hline 15 & que son insultados \\
\hline 16 & que son perseguidos \\
\hline 17 & que son maltratados \\
\hline 18 & que lloran \\
\hline & $\mathrm{Y}$ \\
\hline 19 & hoy Jesús nos dice \\
\hline 20 & "amen a sus enemigos" \\
\hline
\end{tabular}

Aunque el pasaje combina muchos elementos, aquí nos gustaría focalizarnos en las cláusulas con el proceso verbal "decir" (13 y 19) y sus proyectadas (14, $15,16,17$ y $18 ; 20$, respectivamente):

...una de las bienaventuranzas decía: "felices aquellos que son insultados, aquellos que son perseguidos, aquellos que son maltratados, felices aquellos que lloran" (DC-1, [013-015])

Y hoy Jesús nos dice: "amen a sus enemigos". (DC-1, [015])

Como hemos visto, el informe caracterizaba al texto bíblico por su rasgo imperativo. Y esta perspectiva es la que establece el modo en que son leídas las locuciones de las dos cláusulas. En el primer caso, "felices..." queda inmerso en el aspecto obligativo, lo que sugeriría un efecto de sentido del tipo "tienen que / tenemos que ser felices". Este efecto lograría cierta congruencia con la función imperativa del modo subjuntivo de verbo "amar" en la locución de la siguiente cláusula proyectada: "amen".

También señalamos que parte de la reformulación evaluativa del informe consistía en orientar el texto bíblico hacia el hacer como ámbito de la experiencia. $Y$ esto es significativo si consideramos que "ser feliz" o "amar" se presentan como procesos que suelen asociarse a ámbitos de la experiencia interna, mental, del mundo de la conciencia, es decir, relativos al "sentir". El informe trastoca este efecto al otorgarle al texto bíblico una incidencia sobre el hacer, antes que por el ser o el sentir.

Si ubicamos ahora los diferentes estilos y los casos analizados en la tabla, encontramos la siguiente disposición: 


\begin{tabular}{|l|l|l|}
\hline IGLESIA DEL CARMEN & \multicolumn{2}{|l|}{$\begin{array}{l}\text { FORMAS DE LA LOCUCIÓN } \\
\text { EN TANTO OBJETO DEL PROCESO VERBAL }\end{array}$} \\
\hline $\begin{array}{l}\text { El Señor nos dice <todo lo que tenemos que hacer>. } \\
(\text { DC-1, [007-008]) }\end{array}$ & Informe & opacidad \\
\hline $\begin{array}{l}\text { San Pablo dice <que tenemos que predicar a Cristo } \\
\text { oportuna e inoportunamente>. (DC-2, [152-153]) }\end{array}$ & Estilo indirecto \\
\hline $\begin{array}{l}\text { <Como me persiguieron a mí os perseguirán a vo- } \\
\text { sotros y seréis vosotros también perseguidos>, les } \\
\text { decía Cristo. (DC-2, [029-031]) }\end{array}$ & Estilo directo & \begin{tabular}{c} 
transparencia \\
\hline
\end{tabular} \\
\hline
\end{tabular}

\section{DE LA TRANSPARENCIA A LA OPACIDAD: LA PROGRESIÓN DE LOS RECURSOS Y LAS ESTRATEGIAS}

Luego de analizar por separado los recursos que realizan las estrategias de los modos de agentivación del texto bíblico y las de los modos de objetivación del texto bíblico, estamos en condiciones de volver a estos recursos de un modo diferente. Se trata ahora de disponerlos en el plano, en la mesa de trabajo del analista, para poder ver aquello que la progresión, la linealidad y la acumulación del desarrollo apenas permitía intuir.

En esta nueva mirada nos interesa comparar, poner en serie, las clases de recursos que analizamos en este grupo de homilías con los presentes en el resto de los discursos producidos en las homilías de las demás iglesias estudiadas. Este abordaje nos permite identificar nuevos agrupamientos, enriquecimientos y complejizaciones de los mismos, e incluso una cierta progresión capaz de delinear una nueva línea de fuerza, un nuevo aspecto de conflictividad que atraviesa al corpus. En efecto, al reunir en una misma tabla los grupos de recursos relativos al tiempo y la forma del verbo conjugado "decir" de cada una de las iglesias, se nos ofrece la siguiente representación: 


\begin{tabular}{|c|c|c|c|c|}
\hline \multicolumn{5}{|c|}{ MODOS DE OCURRENCIA DEL VERBO CONJUGADO "DECIR" } \\
\hline \multicolumn{5}{|c|}{ Sector céntrico } \\
\hline \multirow[t]{4}{*}{ DEL CARMEN } & S. CORAZÓN DE JESÚS & LA MERCED & Lourdes & \multirow{10}{*}{ opacidad } \\
\hline & & & está queriendo decir & \\
\hline & quiso decir & & quiere decir & \\
\hline & dijo & dijo & dijo & \\
\hline \multirow[t]{4}{*}{ Decía } & decía & decía & decía & \\
\hline & & & va a decir & \\
\hline & & & empieza a decir & \\
\hline & & & está diciendo & \\
\hline \multirow[t]{2}{*}{ Dice } & dice & dice & dice & \\
\hline & & $\varnothing$ & & \\
\hline
\end{tabular}

La organización, de izquierda a derecha responde a un recorrido que va de los recursos relevados en las iglesias céntricas a los presentes en las iglesias barriales o periféricas. Rápidamente es posible reconocer el modo en que la aproximación al grupo de la iglesia de Nuestra Señora de Lourdes conlleva la identificación de un mayor número de recursos. Frente a las dos formas ("dice" y "decía") de las homilías de la iglesia Nuestra Señora Del Carmen, las del Sagrado Corazón agregan dos elementos más ("dijo" y "quiso decir"). Las homilías de la iglesia de Nuestra Señora de la Merced, por su parte, conservan tres de estos elementos ("dijo", "decía" y "dice") y agregan la elipsis. Salvo por este último recurso, que supondría el caso extremo de presentificación del texto bíblico, la progresión, aunque ínfima, lleva a una ampliación de los recursos que trazan una cierta distancia del texto, sea respecto del presente de la interacción ("decía", "dijo"), sea de la transparencia de su significación ("quiso decir"). Este despliegue y complejización alcanza su mayor desarrollo en el último grupo de homilías -iglesia Nuestra Señora de Lourdes-. En este conjunto de recursos, el verbo "decir" asume tres grupos de formas: a) aquellas que lo incorporan a formas perifrásticas con componente durativo ("está diciendo", "empieza a decir" y "va a decir") que le otorgan al proceso verbal un rasgo propio de los de comportamiento; b) las que continúan con el distanciamiento del presente de la interacción discursiva ("decía" y "dijo") ya relevado en los otros grupos; c) las que continúan y amplían la representación de la no transparencia de la significación del texto ("quiere decir" y "está queriendo decir"). 
En suma, a medida que nos desplazamos de las homilías céntricas a las barriales, el decir del texto bíblico deja de ser una mera mostración para transformarse en una acción transformativa (marcada en el aspecto durativo de las formas perifrásticas), que se distancia del presente de la interacción (a través del uso de las formas de pasado) y que busca dar cuenta de una significación antes que de una locución (lo que sugieren las diferentes formas del "querer decir"). Esta progresión que aquí se esboza, es la que la investigación logró mostrar como recurrente en los diferentes conjuntos de recursos.

\section{LA LUCHA POR LA OBTENCIÓN Y LA ADMINISTRACIÓN DEL SENTIDO DEL TEXTO BÍBLICO}

Resta ahora presentar una explicación posible a este fenómeno que nos muestra el análisis comparativo, no sólo del pequeño grupo de estrategias que hemos seleccionado para este artículo, sino también en el resto de las que apenas hemos enunciado. El presente estudio de las estrategias discursivas se ha guiado a partir de ciertos postulados que consideramos relevantes y operativos para la explicación del discurso homilético. Por una parte, hemos derivado la tensión entre autorización y adecuación de la escisión constitutiva del campo religioso, aquella que establece la distinción fundamental entre los agentes encargados de la administración de los bienes de salvación y aquellos que los consumen. Por otra, esta escisión se refuerza en la organización de la Iglesia Católica y en su distribución de las identidades institucionales.

Parte de este análisis implicó una segunda operación teórica, menos evidente, relegada a una suerte de segundo plano de la exposición. En esta operación, el estudio de las homilías colocaba entre paréntesis todo un exterior a la institución, todo un espacio del cual la Iglesia católica también formaba parte y que podía permearse incluso en las cláusulas seleccionadas. Y es la progresión de los recursos relevada en esta segunda parte del presente capítulo lo que hizo evidente la imposibilidad de sostener esa parcialidad y esa parcialización del objeto de estudio. El aumento de recursos que construyen y refuerzan el carácter opaco, complejo, del texto bíblico conforme nos desplazamos de las homilías registradas 
en los sectores céntricos de la ciudad hacia los más barriales y periféricos ya no podía ser explicado en los términos de la contradicción o la paradoja del rito positivo, a través de la aporía del misterio del ministerio. Es necesario considerar entonces a qué otros discursos, a qué otros agentes del campo religioso las homilías extienden sus apelaciones, sus polémicas y, fundamentalmente, sus mecanismos de apropiación del discurso bíblico y su interpretación legítima.

Uno de los supuestos - y prejuicios - que ha operado fuertemente en los estudios del fenómeno religioso en la Argentina es la existencia de una hegemonía y un monopolio religioso de la Iglesia católica en todo el territorio (Frigerio, 2007). Este supuesto, como ha señalado Frigerio, funciona incluso para explicar la diversidad religiosa contemporánea (Esquivel et al., 2001; Mallimacci, 2001, 2003), la cual se establecería en términos de un "antes" y "después" que, "brindando una versión algo estereotipada del pasado monopolizado por el catolicismo, singulariza en demasía lo novedoso de la dinámica religiosa actual" (Frigerio, 2007:89).

Esta representación acerca de la Iglesia católica como agente hegemónico orienta a plantear perspectivas de análisis e hipótesis que reforzaran su carácter independiente, inmanente, $y$, en cierta medida, sustraída de la competencia instaurada por un "mercado religioso" relativamente reciente. Sin embargo, en la medida en que consideramos que la diversidad religiosa no consiste tanto en la creación de un mercado, sino en su desregulación, la atención se focaliza menos en la pérdida de la fe o de una única verdad que en los dispositivos de poder más o menos eficaces para suprimir una disidencia religiosa presente desde mucho antes (Beckford, 2003:83-84).

\section{EL TEXTO BÍBLICO Y LAS FORMAS DE RELIGIOSIDAD POPULAR}

La consideración del discurso católico de las homilías como inmerso en un ámbito de competencia con otros discursos y formas de religiosidad nos permite trazar, entonces, una hipótesis explicativa del gradual aumento de la opacidad del texto bíblico y del reforzamiento de autoridad del sacerdote que hemos relevado. Para esto es necesario recuperar otro fenómeno, de carácter más sociológico que discursivo, y en el que coinciden gran parte de los trabajos 
de los cientistas sociales locales (Mallimaci, 2001; Semán, 2004): la existencia de un activo mercado religioso, con ofertas y demandas diferenciadas, en los barrios y las periferias de nuestro país. ${ }^{9}$

Tal como dejaba ver Frigerio, las diferencias acerca de este fenómeno residen menos en su constatación que en la explicación de su génesis. Mientras algunos autores como Mallimaci consideran que "el antiguo monopolio católico se está resquebrajando [y] la disidencia religiosa estaría mostrando la protesta simbólica de amplios sectores populares" (2001:23). Otros autores, entre ellos Frigerio, con quien coincidimos, plantean que "[l]a desregulación permite que una serie de creencias y prácticas, antes presentes pero de maneras menos desarrolladas y apenas toleradas como "religiosidad popular", sean capitalizadas por diversos grupos que recién en los últimos veinte años pueden actuar libremente" (2007:92).

De este modo es que podemos bosquejar una posible explicación: el aumento de la representación opaca y compleja del texto bíblico en las homilías barriales y periféricas es una respuesta del discurso católico a la disputa con las formas de religiosidad popular presentes y operantes en estos sectores de la ciudad de Santa Fe.

El concepto de "religiosidad popular", como tantos otros que rodean a la práctica y el discurso religioso, ha sido siempre una cuestión polémica. En diferentes períodos, Marisa Massolo (1994) y Eloísa Martín (2007) presentan los recorridos que ha tenido esta noción en los estudios latinoamericanos. Massolo señala un aspecto del debate que quizá responda más a las polémicas políticas vigentes en los años 70 y 80 . Para esta autora, la postura común de los cientistas sociales acerca de la religiosidad popular es la ambivalencia: "[m]ientras que algunos autores consideran que la religiosidad popular 'perpetúa una falsa conciencia sobre la naturaleza de la sociedad de clases', otros alegan que expresa sentimientos de opresión, e incluso que lleva a la rebelión" (1994:101-102). ${ }^{10}$

\footnotetext{
${ }^{9}$ En relación con su trabajo de campo en un barrio del Gran Buenos Aires durante la década del '90, Semán señala que "[p]or cada capilla cristiana nos encontraremos con no menos de cinco o seis pequeñas iglesias pentecostales. Si una capilla católica abarca a los fieles de, supongamos, quince o veinte manzanas, nos encontraremos con que hay una iglesia evangélica cada dos o tres cuadras, lo que no es poco decir" (2004:27).

${ }^{10}$ Ya en un trabajo de 1984 acerca de la bibliografía sobre la religiosidad popular en Brasil, Rubem Fernandes reconocía esta misma ambivalencia entre un "romanticismo" que la pone en valor y un "iluminismo" que postula un mirada crítica, la necesidad de un distanciamiento y educación en aquellos que la practican.
} 
Martín, por su parte, realiza una revisión de los trabajos producidos y publicados en la Argentina desde principios de los años 80 hasta 2007 (año de publicación de su texto) y propone organizarlos en cuatro grupos: 1) la religiosidad popular como la "religión del pueblo"; 2) como respuesta funcional a situaciones de carencia; 3) como "otra lógica"; 4) como conjunto de prácticas de sacralización. Aunque no disponemos del espacio para explicar estos posicionamientos, digamos brevemente que mientras los dos primeros todavía conservan la oposición popular versus institucional, las dos siguientes:

dan cuenta de que muchas de las manifestaciones de la religiosidad popular no son totalmente ajenas a la presencia de alguna institución religiosa; estas relaciones acontecen de modos muchos más complejos que los de dominación/resistencia. De esta manera, estos trabajos muestran que es posible y necesario pensar la religiosidad popular no exactamente por fuera ni contra la Iglesia, sino aconteciendo en un espacio intersticial, de negociación y conflicto, sí, pero donde los intercambios acontecen. (Martín, 2007:74)

Esta aproximación a la religiosidad popular nos habilita a considerar que la polémica que plantean las homilías alcanza a los laicos, a los fieles que participan del rito de la misa. Y esto sería posible considerando lo propuesto por Frigerio, esto es, que el reconocimiento de una determinada identidad religiosa no implica automáticamente la adhesión a un conjunto de creencias y a una cierta legitimidad. De este modo, la homilía católica se constituye en un dispositivo institucional para definir creencias y legitimidades en aquellos espacios sociales donde incluso los católicos declarados pueden participar de prácticas y adherir a creencias propias de las formas de religiosidad popular. ${ }^{11}$

La segunda instancia de este desarrollo demanda centrar nuestra atención en la relevancia del texto bíblico y su interpretación — foco de nuestra mirada

\footnotetext{
${ }^{11}$ En la homilía pronunciada en la iglesia Nuestra Señora de La Merced, el arzobispo de Santa Fe, José María Arancedo, decía: "Una iglesia tiene que ser la presencia viva de Cristo, por eso tiene que ser servidora, comunidad misionera, comunidad servidora. Comunidad de oración también, comunidad de oración. Qué triste cuando la gente puede decir en algunos lugares: bueno, vamos a la iglesia solamente a buscar cosas materiales. Y por ahí después cuando tenemos que rezar, alabar a Dios, decía, en algunos lugares vamos... vamos al culto. La iglesia tiene que ser un lugar de oración" (LM-5, [065-071]).
} 
sobre el corpus - en las formas de religiosidad popular. Esto nos llevaría, en una primera instancia, a la distinción entre el catolicismo - con su monopolio de la interpretación en manos de especialistas - y los grupos evangélicos que continúan la tradición protestante acerca de la posibilidad que tiene cada creyente de acceder a los significados bíblicos sin mediaciones-. Sin embargo, preferimos el planteo de Velho (1995), quien sugiere que, en ciertas circunstancias, estamos frente a un "cristianismo popular", referido a una "cultura bíblica", que demanda relativizar o relocalizar la oposición catolicismo / protestantismo. ${ }^{12}$ Por otro lado, como señala Semán, parte de la actividad de expansión y localización de los grupos evangélicos pentecostales — una de las formas de la religiosidad popular - y de la conformación del perfil de cada iglesia reside en "la dialéctica entre los textos bíblicos y las bases culturales de los sectores que se desarrollan: así nacen estilos específicamente vinculados a la cultura de los jóvenes, de los migrantes rurales o de las clases medias" (2004:44).

Todo esto nos permitiría señalar, entonces, la relevancia que tiene el texto bíblico, su interpretación e incluso su alusión general ${ }^{13}$ en las formas de religiosidad popular con las que disputa la homilía católica como práctica concreta. La opacidad otorgada al texto bíblico en las homilías ("significa", "está representando") y el reforzamiento de la actividad exegética por parte del sacerdote ("tenemos que vincular", "vamos a explicar") serían reacciones de las parroquias católicas ante la amenaza de la pérdida del monopolio interpretativo sobre el texto bíblico en los sectores barriales y periféricos. La necesidad de considerar la pertenencia genérica del texto bíblico, la de inscribirla en una exégesis de tipo histórico-crítica, entre otras operaciones, serían parte de los medios que, según Danièle Hervieu-Leger, utilizaría el discurso católico para mantener su monopolio del poder religioso, el cuales depende: "de la capacidad de la institución de hacer admitir a los laicos lo bien fundado de su exclusión (del poder simbólico)" (Hervieu-Leger, 1986:227; citado por Mallimaci, 2001:19-20).

12 "Normalmente, nas discussões teológicas, o tema da graça é asociado preferencialmente à tradição protestante, e não à católica. Todavia, ele parece surgir naturalmente do material examinado. E o mesmo ocorre, mais acentuadamente ainda, no caso similar do cativeiro-libertaçâo e da própria ênfase no Velho Testamento. Uma hipótese a desenvolver é que em determinado nível está-se diante de um cristianismo popular, referido à 'cultura bíblica', devendo-se relativizar e/ou localizar devidamente a oposição catolicismo-protestantismo" (Velho, 1995:26).

${ }^{13}$ A esto refiere en parte Velho al hablar de una "cultura bíblica". 


\section{CONCLUSIÓN}

Con este recorrido acerca de los modos de entender las formas de religiosidad popular y el rol del texto bíblico en las mismas, creemos haber sustentado y orientado una posible demostración de esta última hipótesis planteada. Los barrios y los sectores periféricos de la ciudad de Santa Fe se transforman así en un espacio intersticial, de negociación y disputa por el establecimiento de creencias y legitimidades, incluso en aquellos laicos católicos que, regularmente, llenan los largos bancos y las naves de las parroquias. El análisis de los discursos, de los recursos y estrategias nos permitió reconocer algunos de los modos que asume la participación católica en ese espacio de conflictividad por el poder religioso.

\section{REFERENCIAS BIBLIOGRÁFICAS}

Arnoux, E. (2003). La reformulación interdiscursiva en Análisis del Discurso. En Actas del Congreso "Análisis del discurso y enseñanza de la lengua". Lima: Universidad Ricardo Palma.

Arnoux, E. y Blanco, M.I. (2002). Otras formas de persuasión. La interpretación de textos bíblicos. En Actas del Congreso Internacional "La argumentación". Universidad de Buenos Aires. Instituto de Lingüística.

- (2004). Polifonía institucional y eficacia persuasiva en los discursos oficiales de la Iglesia Católica Argentina frente a la crisis. En Arnoux, E. y García Negroni, M. (Comps.) Homenaje a Oswald Ducrot. Buenos Aires: Eudeba.

Bajtin, M. (2008 [1979]). Estética de la creación verbal, Buenos Aires: Siglo XXI Editores.

Beckford, J. (2003). Social Theory and Religión, Cambridge: Cambridge University Press. Bourdieu, P. (1991 [1980]). El Sentido Práctico. Madrid: Taurus. - (1993 [1987]). Cosas Dichas. Barcelona: Gedisa.

— (2001 [1985]). ¿Qué significa hablar? Economía de los intercambios lingüísticos. Madrid: Akal.

- (2009). La eficacia simbólica. Religión y política. Buenos Aires: Biblos. 
Briggs, C. y Bauman, R. (1996). Género, intertextualidad y poder social. En Revista de Investigaciones Folklóricas, 11, 78-108.

Brown, P. y Levinson, S. (1989 [1978]). Politeness. Some universals in language use. Cambidge: CUP.

Durkheim, E. (1991 [1912]). Las formas elementales de la vida religiosa. México: Colofón. Eggins, S. (2004). An Introduction to Systemic Functional Linguistics. London: Continuum.

Esquivel, J.; García, F.; Hadida, M. y Houdin, V. (2001). Creencias y religiones en el Gran Buenos Aires: el caso de Quilmes. Buenos Aires: UNQ.

Fairclough, N. (1992) Discourse and Social Change, Cambridge: Polity Press. (1998 [1989]). Language and Power. London: Longman.

Fernandes, R.C. (1984). "Religiões Populares": uma visão parcial da literatura recente. En Bib. O que se deve ler em Ciências Sociais no Brasil, 18, 238-273, São Paulo: ANPOCS-Cortez.

Fernández, M. D. y Ghio, E. (2005). Manual de Lingüística Sistémico Funcional. Santa Fe: Ediciones UNL.

Foucault, M. (1992 [1970]). El orden del discurso. Buenos Aires: Tusquets. (2001 [1969]). La arqueología del saber. Buenos Aires: Siglo XXI Editores.

Frigerio, A. (2007). Repensando el monopolio religioso del catolicismo en la Argentina. En M.J. Carozzi y C.C. Cernadas (Eds.). Ciencias sociales y religión en América Latina. Perspectivas en debate, Buenos Aires: Biblos.

Fuchs, C. (1994). Paraphrase et énonciation. París: Ophrys.

Halliday, M.A.K. (1994 [1985]). Introduction to Functional Grammar. London: Arnold. Halliday, M.A.K. y Matthiessen, C. (2004). An Introduction to Functional Grammar. London: Arnold.

Hunston, S. (2002). Corpora in Applied Linguistics, Cambridge: Cambridge University Press.

Mallimacci, F. (2001). Prólogo. En Esquivel, J, F. García, M. Hadida y V. Houdin, Creencias y religiones en el Gran Buenos Aires: el caso de Quilmes, Buenos Aires: UNQ.

- (2003). Globalización y catolicismos: La mirada desde arriba y las relaciones cotidianas. Conferencia Magistral Pronunciada en el evento internacional: Globalización y diversidad religiosa, realizado en la Facultad de Ciencias Humanas, Universidad Nacional de Colombia, Bogotá.

Martín, E. (2007). Aportes al concepto de «religiosidad popular»: una revisión de 
la bibliografía argentina. En Carozzi, M.J. y C.C. Cernadas (Eds.). Ciencias sociales y religión en América Latina. Perspectivas en debate, Buenos Aires: Biblos.

Martin, J. y Rose, D. (2007). Genre Relations. Mapping Culture, London: Equinox. Martin, J.; Matthiessen, C. y Painter, C. (1997). Working With Functional Grammar, London: Arnold.

Massolo, M. (1994). El estudio de la religiosidad popular en Latinoamérica y Europa: perspectivas recientes. En Frigerio, A. y Carozzi, M. (Comps.). El estudio científico de la religión a fines del siglo XX. Buenos Aires: CEAL.

Menéndez, S.M. (1997). ¿Cómo pedir dinero en el Buenos Aires del siglo XVIII? Un enfoque pragmático-histórico-discursivo (523-532). En Actas del IV Congreso Internacional de Historia de la Lengua Española. Tomo II. Logroño: Universidad de La Rioja. - (1998). Léxico y estrategias discursivas: un enfoque socio-cognitivo (137-147). En Cifuentes Honrubia, J.L. (Ed.). Estudios de lingüística cognitiva I. Alicante: Universidad de Alicante.

(2000). Estrategias discursivas: principio metodológico para el análisis pragmático del discurso. En Lengua, discurso, texto: I Simposio internacional de análisis del discurso, 1, 923-946 (Lengua, discurso, texto. I.).

(2002). Estrategias discursivas en el discurso epistolar de Hispanoamérica (siglos XVI a XVIII) (1283-1294). En Actas del V Congreso Internacional de Historia de la Lengua Española. Madrid: Gredos.

- (2004). ¿Qué es una estrategia discursiva? En Actas del Congreso Internacional: Debates Actuales. Las teorías críticas de la literatura y la lingüística. Buenos Aires.

- (2005). Gramática, Análisis del Discurso e Interpretación Crítica: las relaciones no tan evidentes. En Proceedings of International Conference on Critical Discourse Analysis. Universidad de Valencia.

- (2006). ¿Qué es una gramática textual?, Buenos Aires: Littera.

Semán, P. (2004). La religiosidad popular. Creencias y vida cotidiana. Buenos Aires: Capital Intelectual.

Thompson, G. (2004). Introducing Functional Grammar. London: Arnold.

Velho, O. (1995). Besta-Fera: recriação do mundo. Ensaios Críticos de Antropologia. Rio de Janeiro: Relume-Dumará.

Verschueren, J. (1999). Understanding Pragmatics. London: Arnold.

Wodak, R. y Meyer, M. (2003 [2001]). Métodos de análisis crítico del discurso. Barcelona: Gedisa. 
REFERENCIAS DEL CORPUS

\begin{tabular}{|l|l|l|l|l|}
\hline Iglesia & Ubicación & Fecha & Duración & Notación \\
\hline Ntra. Sra. Del Carmen & La Rioja 2561 & $22 / 03 / 04$ & $14^{\prime} 27^{\prime \prime}$ & DC-1 \\
\hline & & $23 / 05 / 04$ & $14^{\prime} 24^{\prime \prime}$ & DC-2 \\
\hline & & $30 / 05 / 04$ & $12^{\prime} 36^{\prime \prime}$ & DC-3 \\
\hline & & $05 / 06 / 04$ & $12^{\prime} 40^{\prime \prime}$ & DC-4 \\
\hline & & $10 / 07 / 04$ & $15^{\prime} 36^{\prime \prime}$ & DC-5 \\
\hline
\end{tabular}

\section{CONVENCIONES UTILIZADAS PARA LA TRANSCRIPCIÓN}

\begin{tabular}{|c|c|}
\hline / & Pausa corta inferior a medio segundo. \\
\hline$/ /$ & Pausa de medio segundo. \\
\hline$/ / /$ & Pausa de un segundo. \\
\hline$\left(2^{\prime \prime}\right),\left(3^{\prime \prime}\right),\left(4^{\prime \prime}\right)$ & Se indica el número de segundos en las pausas de más de un segundo. \\
\hline$\uparrow$ & Comienzo de entonación ascendente. \\
\hline$\downarrow$ & Comienzo de entonación descendente. \\
\hline$\rightarrow$ & $\begin{array}{l}\text { Entonación mantenida. Se utilizará para señalar el fin de los pasajes } \\
\text { ascendentes o descendentes. }\end{array}$ \\
\hline [ac.] & Ritmo acelerado. \\
\hline [le.] & Ritmo lento. \\
\hline Subrayado & Pronunciación enfática \\
\hline MAYÚSCULAS & Pronunciación más enfática. \\
\hline ¿? & Interrogación. \\
\hline $\mathrm{i} !$ & Exclamaciones. \\
\hline$::$ & $\begin{array}{l}\text { Alargamiento de un sonido. Múltiples dos puntos indican una mayor } \\
\text { extensión del sonido. }\end{array}$ \\
\hline$\ldots-$ & Corte abrupto en medio de una palabra. \\
\hline${ }^{\circ}$ palabra ${ }^{\circ}$ & $\begin{array}{l}\text { Los "símbolos de grado" indican que las palabras han sido dichas en } \\
\text { una intensidad menor. }\end{array}$ \\
\hline$(())$ & Palabra no audible o no reconocible. \\
\hline ((palabras)) & Transcripción dudosa. \\
\hline$(($ palradse ?)) & $\begin{array}{l}\text { Cuando la duda es mayor y no es posible identificar la palabra, } \\
\text { se consignan las sílabas sin sentido y se agrega un signo de pregunta. }\end{array}$ \\
\hline$(($ tos $))$ & $\begin{array}{l}\text { doble paréntesis indica otro tipo de características del audio material } \\
\text { además de las verbalizaciones. }\end{array}$ \\
\hline
\end{tabular}

